\title{
Quercetin induced apoptosis in association with death receptors and fludarabine in cells isolated from chronic lymphocytic
} leukaemia patients

\author{
M Russo', C Spagnuolo', S Volpe ${ }^{2}$, A Mupo', I Tedesco' and G-L Russo*,I \\ 'Institute of Food Sciences, National Research Council, Avellino 83100, Italy; ${ }^{2}$ Onco-Haematology Division, SG Moscati Hospital, Avellino 83100, Italy
}

BACKGROUND: Quercetin is a flavonoid naturally present in food and beverages belonging to the large class of phytochemicals with potential anti-cancer properties. Here, we investigated the ability of quercetin to sensitise primary cells from chronic lymphocytic leukaemia (CLL) to death receptor (DR) agonists, recombinant TNF-related-apoptosis-inducing ligand (rTRAIL) and anti-CD95, and to fludarabine, a widely used chemotherapeutic drug against CLL.

METHODS: Peripheral white blood cells were isolated from patients and incubated with medium containing 50 ng ml anti-CD95 agonist antibody; $10 \mathrm{ng} \mathrm{ml}$ recombinant TRAIL; 10-25 $\mu \mathrm{M}$ quercetin and 3.5-14 $\mu \mathrm{M}$ fludarabine. Neutral Red assay was used to measure cell viability, where as apoptosis was assessed by determining caspase-3 activity, exposure to Annexin $\vee$ and PARP fragmentation.

RESULTS: Quercetin significantly enhanced anti-CD95- and rTRAIL-induced cell death as shown by decreased cell viability, increased caspase-3 and -9 activities, and positivity to Annexin $\mathrm{V}$. In addition, association of quercetin with fludarabine increases the apoptotic response in CLL cells of about two-fold compared with quercetin monotreatment.

CONCLUSION: This work shows that resistance to DR- and fludarabine-induced cell death in leukaemic cells isolated from CLL patients can be ameliorated or bypassed by the combined treatment with quercetin. Considering the low toxicity of the molecule, our study results are in favour of a potential use of quercetin in adjuvant chemotherapy in combination with other drugs.

British Journal of Cancer (2010) I 03, 642-648. doi:I0.1038/sj.bjc.6605794 www.bjcancer.com

Published online 20 July 2010

(c) 2010 Cancer Research UK

Keywords: chronic lymphocytic leukaemia; apoptosis; TRAIL; CD95; fludarabine; quercetin

Chronic lymphocytic leukaemia (CLL) is the most frequent form of leukaemia in adult population $(22-30 \%$ of all leukaemia cases) with an incidence projected to be between 1 and 5.5 per 100000 people in the Western world (Yee and O'Brien, 2006). Approximately, 50\% of CLL patients remain asymptomatic and are diagnosed by unrelated lymphocytosis. Treatment depends on the clinical staging (Rai or Binet classification) and, originally, included conventional therapy based on alkylating/anthracycline agents. The introduction in therapy of fludarabine, a purine analogue, substantially improved overall and complete responses when used both as monotherapy (Johnson et al, 1996) and in association with alkylating agents (Eichhorst et al, 2006). Recently, treatment with humanised monoclonal antibodies, such as rituximab and alemtuzumab has been used as induction therapy and in patients with refractory CLL (Yee and O'Brien, 2006). In these patients, modest improvement has been achieved with rituximab or combined chemotherapy. Despite this, a significant percentage of untreated patients (up to 37\%) do not respond to fludarabine treatment, or become refractory to this regime of treatment (up to $76 \%$ ). Moreover, a variable number of these subjects occasionally incur in severe side effects, such as neutropenia, suppression of helper T cells, acute tumour lysis syndrome, autoimmune haemolysis, and neurotoxicity (Yee and O'Brien, 2006).

Cell death evasion and progressive accumulation of $\mathrm{B}$ cells are the major relevant events in CLL pathogenesis, so targeting

*Correspondence: Dr G-L Russo; E-mail: glrusso@isa.cnr.it

Revised 19 May 20 I0; accepted 17 June 20 I0; published online 20 July 2010 apoptotic pathways triggered by CD95 (Fas/Apo-1) and TNFrelated-apoptosis-inducing ligand (TRAIL)/Apo-2 death receptors (DRs) has been suggested as novel therapeutic approaches to treat this leukaemia (Pleyer et al, 2009). CD95 and TRAIL belong to the TNF receptor superfamily regulating the extrinsic apoptotic pathways after the interaction with their cognate ligand. Both CD95 and TRAIL are potential candidates to target apoptosis in malignant cells (Debatin and Krammer, 2004; Papenfuss et al, 2008; Russo et al, 2010). However, one drawback of this therapeutic strategy is the resistance to DR-induced cell death in B-CLL patients (MacFarlane et al, 2002, 2005).

In this context, a plethora of naturally occurring molecules with chemopreventive properties have been suggested as potential candidates in adjuvant chemotherapy when associated with other drugs (Aggarwal and Shishodia, 2006; Mansour et al, 2007; Russo, 2007; Fimognari et al, 2008). In this article, we show that quercetin $\left(3,3^{\prime}, 4^{\prime}, 5,7\right.$-pentahydroxyflavone), a naturally occurring flavonoid widely present in fruits and beverages (Lamson and Brignall, 2000; Day et al, 2003) and possessing anti-cancer activity (Russo, 2007; Bischoff, 2008; Murakami et al, 2008), is able to sensitise leukaemic cells isolated from CLL patients when associated with recombinant TRAIL (rTRAIL) or anti-CD95 agonistic antibody. We also showed that quercetin potentiates the effect of fludarabine on resistant B-CLL cells. The rationale for investigating the sensitising effect of quercetin on CLL derives from previous works on leukaemic cell lines showing the apoptogenic activity of the molecule on cell lines resistant to DR-induced cell death (Russo et al, 1999, 2003, 2007). 
To the best of our knowledge, this is the first study to show the anticancer and apoptogenic effects of quercetin at relatively low concentrations $(10-25 \mu \mathrm{M})$ in primary tumour cells.

\section{MATERIALS AND METHODS}

\section{Reagents}

Roswell Park Medium Institute (RPMI) medium, L-glutamine $200 \mathrm{~mm}$, penicillin $5000 \mathrm{IU} \mathrm{ml}^{-1} /$ streptomycin $5000 \mu \mathrm{g} \mathrm{ml}^{-1}$ and phosphate-buffered saline (PBS) tablets were purchased from Invitrogen (S Giuliano Milanese, Milan, Italy). Neutral red $0.33 \%$ solution, propidium iodide, Trypan blue solution $(0.4 \%)$, quercetin, and dimethyl sulfoxide (DMSO) were from Sigma-Aldrich (Milan, Italy). Annexin V-FITC, rTRAIL (super killer TRAIL), caspase-3 and -9 substrates were from Enzo Life Sciences (AG Lausen, Switzerland). Anti-CD95 (clone CH-11) was from Immunotech (Marseille, France). Fludarabine phosphate was gifted by Onco-Haematology Division, SG Moscati Hospital (Avellino, Italy), participating in this study.

\section{Cell isolation and viability tests}

Mononuclear cells (leukaemic cells $>90 \%$ ) were isolated from peripheral blood of 47 patients with B-CLL. All clinical samples were obtained after informed consent. Following density-gradient centrifugation (Ficoll-Paque Plus; GE Healthcare, Milan, Italy), cells were washed three times in PBS, counted with Trypan blue dye to assess their viability (cell viability $>95 \%$ ), and were immediately cultured in RPMI supplemented with $1 \%$ penicillin/ streptomycin, $2 \mathrm{mM}$ L-glutamine and $10 \%$ autologous serum (Bomstein et al, 2003), at $37^{\circ} \mathrm{C}$ in a humidified atmosphere containing $5 \% \mathrm{CO}_{2}$. For neutral red assay (Fautz et al, 1991), we cultured the cells at density of $1 \times 10^{6}$ per $\mathrm{ml}$ in 48 multi-well plates and incubated $(24-48 \mathrm{~h})$ in a medium containing $0.1 \%$ DMSO, $10-25 \mu \mathrm{M}$ quercetin solubilised in $0.1 \%$ DMSO, rTRAIL $\left(10 \mathrm{ng} \mathrm{ml}^{-1}\right)$, anti-CD95 $\left(50 \mathrm{ng} \mathrm{ml}^{-1}\right)$, or fludarabine dissolved in PBS (3.5-14 $\mu \mathrm{M}$ final concentration). Cell viability assay was performed as described (Russo et al, 2003).

\section{Apoptosis assays}

Phosphatidylserine exposure was measured using the binding of fluorescein-isothiocyanate-labelled (FITC) Annexin V to phosphatidylserine, as per the manufacturer's protocol (Enzo Life Sciences). Briefly, cells $\left(2 \times 10^{6}\right.$ per ml) were washed in PBS and suspended in binding buffer (10 mM HEPES ( $\mathrm{pH} 7.4$ ); $140 \mathrm{~mm} \mathrm{NaCl} ; 2.5 \mathrm{~mm}$ $\left.\mathrm{CaCl}_{2}\right)$. Annexin V FITC $(5 \mu \mathrm{l})$ and propidium iodide $(10 \mu \mathrm{l})$ were added to the cells for $10-15 \mathrm{~min}$ in the dark at room temperature and analysed with flow cytometer (FACSCalibur; Becton Dickinson, Mountain View, CA, USA) equipped with argon laser $(488 \mathrm{~nm})$ and filtered at 530 and $585 \mathrm{~nm}$ for FITC and phycoerythrin respectively. Low fluorescence debris and necrotic cells, permeable to propidium iodide, were gated out before to analysis and 10-20 000 events were collected. Data were analysed using CellQuest software (Becton Dickinson). This assay was also used to measure spontaneous apoptosis in freshly isolated B-CLL cells.

For caspase- 3 and -9 enzymatic activities, we incubated cells $\left(2 \times 10^{6}\right.$ per $\left.\mathrm{ml}\right)$ for $12-16 \mathrm{~h}$ as described above for the cell viability test. At the end of incubation, cells were washed twice in PBS and suspended in lysis buffer (10 mM HEPES (pH 7.4), $2 \mathrm{~mm}$ ethylenediaminetetraacetic acid, $0.1 \%$ 3-((3-cholamidopropyl)dimethylammonio)-1-propanesulfonate, $5 \mathrm{~mm}$ dithiothreitol, $1 \mathrm{mM}$ phenylmethylsulfonylfluoride, $10 \mu \mathrm{g} \mathrm{ml}^{-1}$ pepstatin-A, $10 \mu \mathrm{g} \mathrm{ml}^{-1}$ apronitin, $20 \mu \mathrm{g} \mathrm{ml}^{-1}$ leupeptin). Following measurement of protein concentration (Bradford, 1976), cell extracts were added with reaction buffer and the respective conjugated amino4-trifluoromethyl coumarin (AFC) substrates, for example,
benzyloxycarbonyl-Asp(OMe)-Glu(OMe)-Val-Asp(OMe)-AFC(ZDEVD-AFC)for caspase-3 and LEHD-AFC for caspase-9 (carbobenzoxy-Asp-Glu-Val-Asp and Leu-Glu-Hys-Asp-AFC) before incubation at $37^{\circ} \mathrm{C}$ for $30 \mathrm{~min}$. Upon proteolytic cleavage of the substrates by the different caspases, the free fluorochrome AFC was detected by a spectrofluorometer multiplate reader (FL-500; Bio-Tek Instruments, Milan, Italy) with excitation and emission setting of $395 \pm 20$ and $530 \pm 20 \mathrm{~nm}$ respectively. To quantify enzymatic activities, we determined an AFC standard curve. Caspase-specific activities were calculated as nmol of AFC produced per min per $\mu \mathrm{g}$ proteins at $37^{\circ} \mathrm{C}$ at saturating substrate concentrations $(50 \mu \mathrm{M})$ (Russo et al, 2003). Fold increase in caspase- 3 and -9 activities was determined by direct comparison with the level of DMSO-treated cells.

\section{Immunoblot}

Cleavage of poly(ADP-ribose) polymerase (PARP) in B-CLL cells was revealed by immunoblotting using anti-PARP monoclonal antibody (Santa Cruz Biotechnology, Heidelberg, Germany) as described (Russo et al, 2007). B-CLL cells $\left(2 \times 10^{6}\right.$ per ml) were suspended in lysis buffer containing $150 \mathrm{~mm} \mathrm{NaCl}, 50 \mathrm{~mm}$ Tris- $\mathrm{HCl}$ $(\mathrm{pH}$ 7.4), $5 \mathrm{mM}$ ethylenediaminetetraacetic acid, $1 \%$ NP-40, $0.5 \mathrm{~mm}$ dithiothreitol, $1 \mathrm{mM} \mathrm{Na} \mathrm{VO}_{4}, 40 \mathrm{~mm} \mathrm{NaF}, 1 \mathrm{mM} \mathrm{Na}{ }_{4} \mathrm{P}_{2} \mathrm{O}_{7}$, $7.4 \mathrm{mg} \mathrm{ml}^{-1} 4$-p-nitrophenyl phosphate, $10 \%$ glycerol, $100 \mu \mathrm{g} \mathrm{ml}^{-1}$ phenylmethylsulfonyl fluoride and a cocktail of inhibitors 'complete' by Roche Applied Science (Monza, Milan, Italy).

Total protein lysates $(20-25 \mu \mathrm{g})$ were loaded on a $12 \%$ pre-cast gel (CRITERION XT; Bio-Rad Laboratories, Segrate, Milan, Italy) and blotted onto polyvinylidene difluoride (PVDF), hybond-P membrane (GE Healthcare). The membrane blot was rinsed with T-TBS $(0.1 \%$ Tween 20, $25 \mathrm{~mm}$ Tris, $137 \mathrm{~mm} \mathrm{NaCl}, 2.69 \mathrm{~mm} \mathrm{KCl} \mathrm{(pH}$ $8)$ ) and blocked by $5 \%(w / v)$ non-fat dry milk in T-TBS for $1 \mathrm{~h}$ at room temperature. Subsequently, the membrane was incubated for $16 \mathrm{~h}$ at $4^{\circ} \mathrm{C}$ with anti-PARP antibody and finally incubated with anti-mouse horseradish-peroxidase-linked secondary antibody (GE Healthcare). The immunoblots were developed using Western Lightening Chemiluminescence Reagent Plus (PerkinElmer; Monza, Milan, Italy).

\section{RESULTS}

We first showed that quercetin enhances DR-induced cell death in leukaemic cells resistant to apoptotic stimuli (Russo et al, 1999, 2007); subsequently, others confirmed our original observation on cell lines of different origin (Psahoulia et al, 2007; Kim et al, 2008a, b; Siegelin et al, 2009). However, to date, the pro-apoptotic effects of quercetin have not been investigated in cells isolated from primary tumours. The rationale of this work was to show if the sensitising effect of quercetin towards DR-induced cell death was confirmed in B cells isolated from CLL patients. To this aim, we isolated mononuclear cells (leukaemic cells >90\%) from peripheral blood of 47 patients with CLL whose clinical features are reported in Table 1. The diagnosis of CLL was established by examination of the blood and bone marrow, including immunophenotype of the malignant lymphocytes according to IWCLL criteria (Hallek et al, 2008). These patients were either untreated or had not received treatment during the previous 6 months. The median age at diagnosis was 62 years (range $32-80$ ) with a male to female ratio of $1: 1$. At diagnosis the distribution of Rai stages I, II, III, and IV was $0,57,2$, and $41 \%$ respectively. Several molecules that modify B-cell receptor signalling, such as ZAP-70 or CD38, as well as immunoglobulin variable heavy chain gene mutation status show important prognostic power in B-CLL at early clinical stage (Pleyer et al, 2009). Table 1 reports positivity to CD38, which is associated to both survival and proliferation in B-CLL cells. CD38 expression and signalling capacity are also linked to progression 
Table I Clinical features of CLL patients

\begin{tabular}{|c|c|c|c|c|c|}
\hline Patient & Sex & Age & Stage (Rai) & CD38 ${ }^{+a}$ & $W_{B C}{ }^{b}$ \\
\hline CLL-69 $9^{\circ}$ & $\mathrm{F}$ & 75 & IV & & 68400 \\
\hline CLL- $67^{\mathrm{d}}$ & M & 70 & $\|$ & & 66200 \\
\hline CLL- $66^{\mathrm{d}}$ & $M$ & 80 & IV & 3 & 63400 \\
\hline CLL-62 & $\mathrm{F}$ & 43 & $\|$ & 2 & 68000 \\
\hline CLL-6/ $\left.\right|^{c, d}$ & $\mathrm{~F}$ & 62 & $\|$ & & 70000 \\
\hline CLL-60 $0^{c, d}$ & $\mathrm{~F}$ & 72 & $\|$ & 97 & 77000 \\
\hline CLL-58 & $\mathrm{F}$ & 75 & $\|$ & 3 & 65000 \\
\hline CLL-57 & M & 65 & $\|$ & 2 & 62800 \\
\hline CLL-56 $6^{c, d}$ & M & 68 & $\|$ & 20 & 72000 \\
\hline CLL-55 $55^{c, d}$ & $M$ & 64 & $\|$ & 1 & 59000 \\
\hline CLL-53 & M & 52 & $\|$ & & 12000 \\
\hline CLL-52 ${ }^{c}$ & $\mathrm{~F}$ & 49 & $\|$ & & 80100 \\
\hline CLL-5I & M & 72 & IV & 7 & 60500 \\
\hline CLL-50 & $\mathrm{F}$ & 32 & $\|$ & 8 & 51500 \\
\hline CLL-49' & M & 57 & IV & 42 & 50000 \\
\hline CLL-47 & M & 37 & IV & 3 & 66900 \\
\hline CLL-46 $6^{c, d}$ & $\mathrm{~F}$ & 51 & $\|$ & 2 & 77000 \\
\hline CLL-45 $45^{c, d}$ & M & 64 & $\|$ & 1 & 59900 \\
\hline CLL-44 & $\mathrm{F}$ & 62 & IV & 60 & 67200 \\
\hline CLL-43 & M & 75 & $\|$ & 0 & 57000 \\
\hline CLL-42 ${ }^{c}$ & M & 78 & IV & & 82200 \\
\hline CLL-4I ${ }^{c, d}$ & $\mathrm{~F}$ & 65 & IV & 2 & 56600 \\
\hline CLL-40 $40^{c, d}$ & $\mathrm{~F}$ & 66 & IV & 98 & 77500 \\
\hline CLL-39 $9^{c, d}$ & M & 62 & IV & 33 & 98000 \\
\hline CLL-38 & $\mathrm{F}$ & 72 & $\|$ & 6 & 66500 \\
\hline CLL-35 & $\mathrm{F}$ & 60 & $\|$ & & 91100 \\
\hline CLL-34 & $\mathrm{F}$ & 60 & $\|$ & 74 & 50000 \\
\hline CLL-33 & $\mathrm{F}$ & 30 & 0 & & 16000 \\
\hline CLL-32 $2^{\mathrm{c,d}}$ & M & 66 & $\|$ & 0 & 63000 \\
\hline CLL-30 & M & 54 & IV & 6 & 46000 \\
\hline CLL-29 $9^{c, d}$ & M & 63 & IV & & 56300 \\
\hline CLL-28 $28^{c, d}$ & M & 48 & $\|$ & 0 & 89200 \\
\hline CLL-27 & M & 75 & III & 1 & 140000 \\
\hline CLL-26 $6^{\mathrm{c,d}}$ & M & 65 & $\|$ & 10 & 62000 \\
\hline CLL-25 $5^{c, d}$ & $\mathrm{~F}$ & 71 & IV & 15 & 65900 \\
\hline CLL-24 & $\mathrm{F}$ & 60 & $\|$ & 56 & 82500 \\
\hline CLL-23 & M & 56 & $\|$ & 78 & 57900 \\
\hline CLL-22 $2^{c, d}$ & $\mathrm{~F}$ & 32 & IV & & 135000 \\
\hline CLL-20 & $M$ & 62 & $\|$ & 6 & 85900 \\
\hline CLL-19 & $\mathrm{F}$ & 74 & IV & 97 & 105000 \\
\hline$C L L-18^{d}$ & M & 62 & IV & 89 & 55800 \\
\hline CLL- 17 & $\mathrm{~F}$ & 76 & $\|$ & 2 & 65400 \\
\hline CLL- 16 & M & 65 & IV & 0 & 49200 \\
\hline CLL- $15^{\mathrm{c,d}}$ & $\mathrm{F}$ & 77 & $\|$ & 92 & 84100 \\
\hline CLL- $14^{c, d}$ & $\mathrm{~F}$ & 63 & $\|$ & I & 65400 \\
\hline CLL- 12 & M & 59 & $\|$ & 0 & 80000 \\
\hline CLL- | | | & $\mathrm{F}$ & 74 & IV & & 40000 \\
\hline
\end{tabular}

Abbreviations: $\quad C L L=$ chronic lymphocytic leukaemia; $M=$ male; $F=$ female;

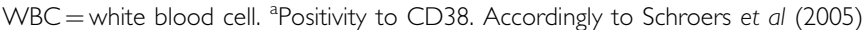
a $30 \%$ cut-off point was used; that is, the samples were considered CD38 positive if the antigen was present in $30 \%$ or more tumor cells and negative if expression was present in less than $30 \%$ cells. ${ }^{b} n$ of cells per $\mu$ l whole blood. 'Samples analysed in Figure 4. ${ }^{\mathrm{d}}$ Samples analysed in Figure 1 .

and response to therapy (Damle et al, 1999). However, in this study, no statistical correlation has been measured between enhanced CD38 expression and cell death induced by quercetin treatment (Supplementary Figure S1).

Owing to the well-known heterogeneity of B-CLL cells, a preliminary screening was performed to determine sensitivity to quercetin, anti-CD95, and rTRAIL (data not reported). This analysis allowed us to address two essential points: (1) to confirm that all B-CLL samples were partially or totally resistant to antiCD95 or rTRAIL treatments, accordingly to data reported in the literature previously (MacFarlane et al, 2002, 2005); (2) to establish the correct range of quercetin concentrations to avoid cytotoxic doses of quercetin that could mask the ability of the molecule to sensitise B-CLL cells to DR-dependent apoptosis. Therefore, in this arm of the study, we excluded samples extremely sensitive to

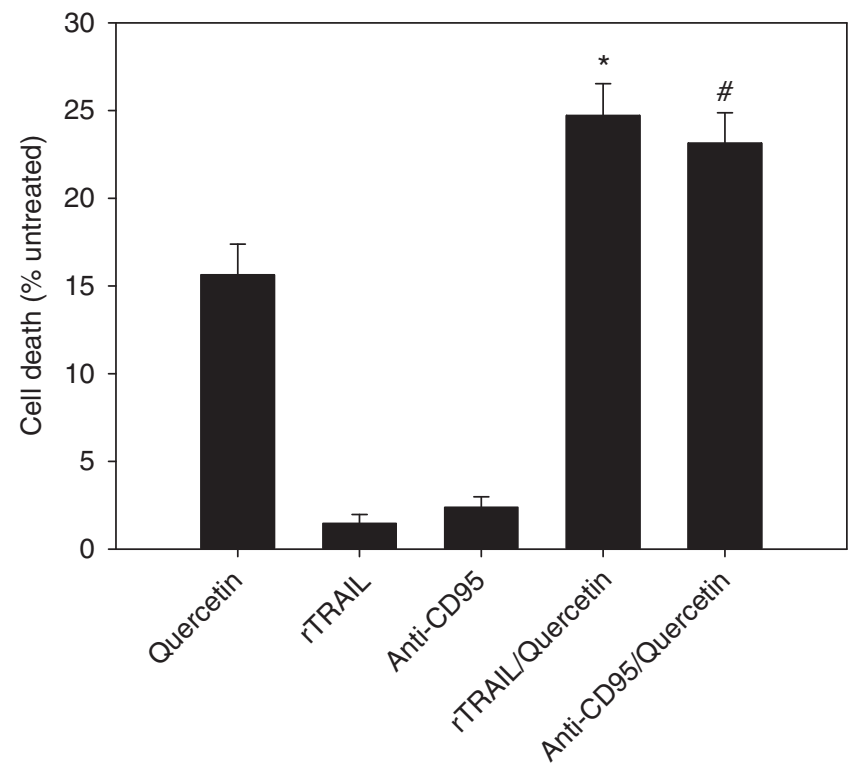

Figure I Cell viability assay in cells isolated from CLL patients and treated with quercetin and anti-CD95 or rTRAIL. Concentrations are as reported in Table 2. Values are presented as mean \pm s.e. $(n=29)$ and significant differences were calculated using the two-tailed paired t-test. Asterisk (*) indicates significant difference from quercetin $(P<0.00 \mathrm{I})$ and rTRAIL $(P<0.000 \mathrm{I})$, whereas $(\#)$ indicates significant difference from quercetin $(P<0.00 \mathrm{I})$ and anti-CD95 $(P<0.000 \mathrm{I})$.

quercetin (decrease in cell viability higher than 30\%; data not shown) and focused our analyses on cells resistant to DR-induced apoptosis (indicated by footenote $\mathrm{d}$ in Table 1).

Cell viability assays (Figure 1) indicate that quercetin potentiates sensitivity to anti-CD95 and rTRAIL treatment with an increase in death cells of about 1.5- and 1.6-fold respectively, when compared with quercetin monotreatment. This effect is statistically significant, as indicated in Figure 1, and suggests the presence of two parallel events acting on B-CLL cells, both triggered by quercetin: (1) sensitisation to DR-induced apoptosis, and (2) apoptotic/ cytotoxic effect of quercetin per se. It is noteworthy that cell viability assay (neutral red) applied to data presented in Figure 1 measured dead cells, without discriminating between apoptosis and necrosis. Therefore, to confirm that the combined treatment of quercetin in association with anti-CD95/rTRAIL triggers apoptotic pathways in B-CLL cells reported in Figure 1, we assayed canonical markers of DR-induced apoptosis in selected samples (Table 2). Reduced cell viability parallels with increased caspase- 3 activity and increased percentage of cells positive to Annexin V, a canonical marker of apoptotic events. Cases reported in Table 2 have been selected based on several criteria: (1) to show that the effects of quercetin in enhancing DR-induced cell death in terms of decrease in cell viability, caspase-3 activation, and Annexin V positivity are more than additive (arrows), supporting the apoptogenic sensitising capacity of quercetin (CLL-55, 56, 44, and 11); (2) to show that a limited percentage of samples (about $10 \%)$ isolated from B-CLL patients neither respond to quercetin, nor to the combined treatment (CLL-42), even if a transient increase in caspase- 3 was detected. Probably, the measured activation of caspase- 3 was not sufficient to exceed the minimal threshold necessary to trigger apoptosis; (iii) to highlight that in about $60-70 \%$ of CLL samples studied, quercetin per se induces apoptosis, as indicated by decreased cell viability and increased caspase-3 activity and Annexin V positivity (CLL-55, 44, and 11). In the remaining cases, an example is CLL-56, the molecule is simply cytotoxic or triggers caspase-independent events, as evidenced by a limited caspase- 3 activity and Annexin V positivity. 
Table 2 Effects of quercetin on anti-CD95- and rTRAIL-induced apoptosis in cells isolated from CLL patients

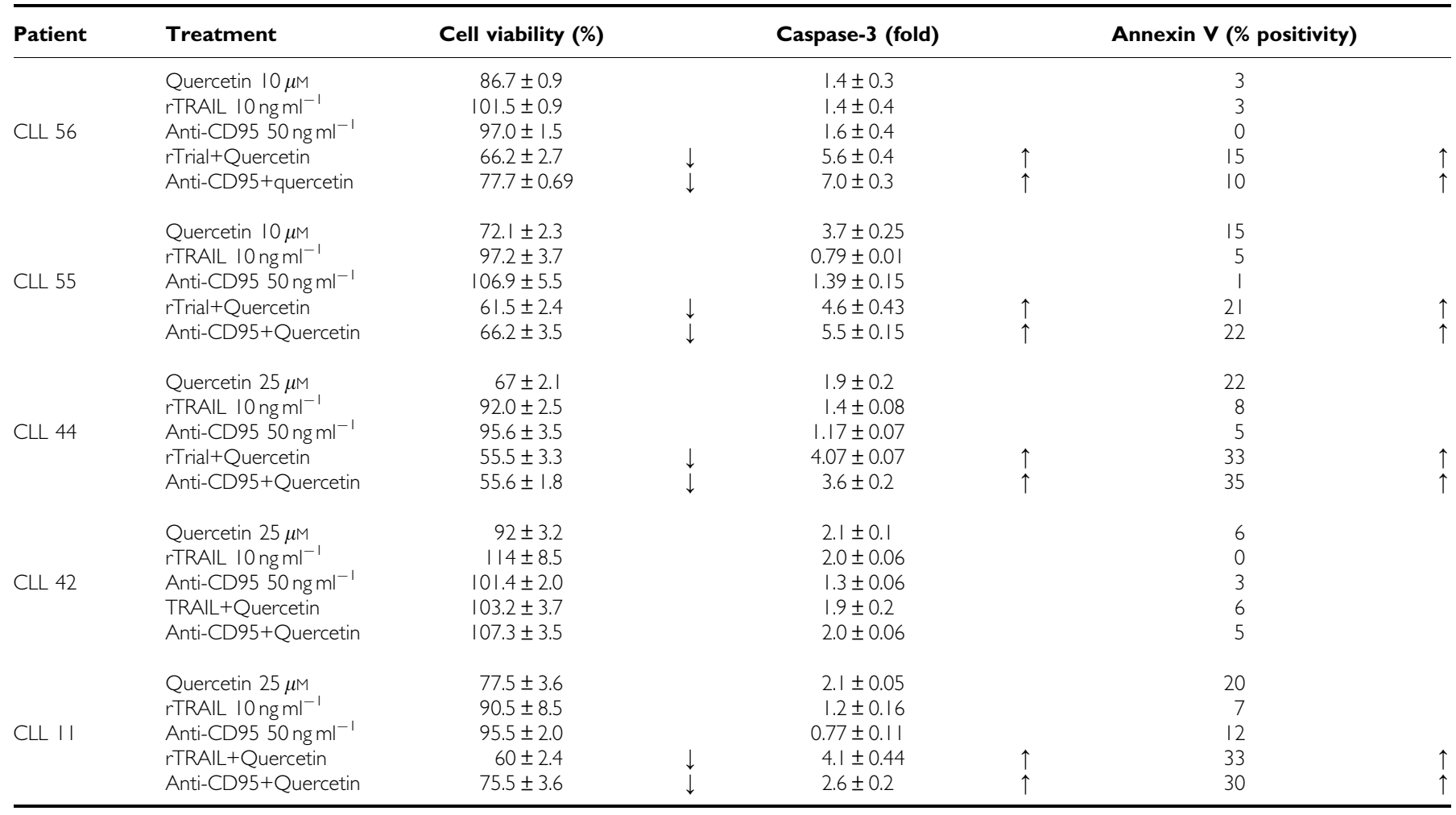

Abbreviations: $\mathrm{CLL}=$ chronic lymphocytic leukaemia; $r$ TRAIL = recombinant TNF-related-apoptosis-inducing ligand. Arrows indicate that the decrease $(\downarrow)$ in cell viability, or the increase $(\uparrow)$ in caspase-3 activity and Annexin $\vee$ positivity were more than additive with respect to single treatments with quercetin, anti-CD95, or rTRAlL. Percentage of Annexin $\vee$ positivity was calculated subtracting basal values ranging between 10 and $30 \%$.
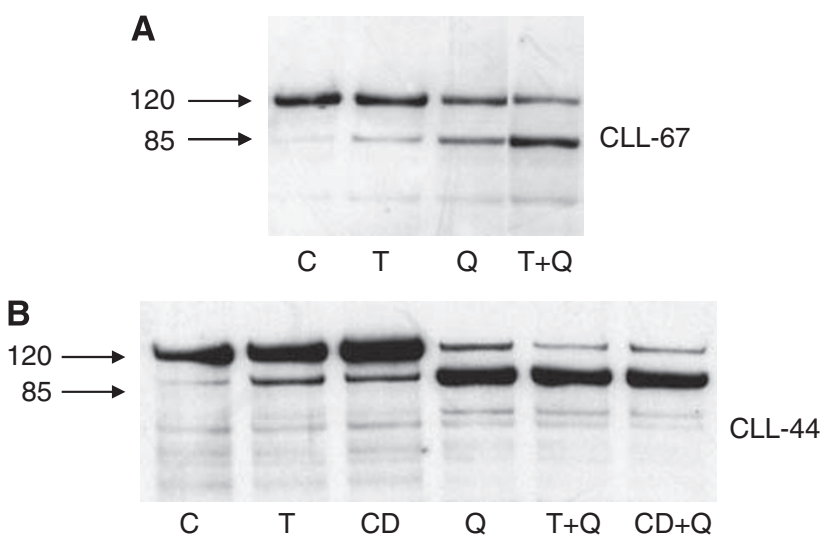

Figure 2 Cleavage of PARP in cells isolated from CLL patients. Immunoblottings show the proteolytic cleavage of PARP by caspase- 3 in two selected samples isolated from CLL patients (CLL-67 and CLL-44 in panels $\mathbf{A}$ and $\mathbf{B}$ respectively). Cells from CLL-44 were treated as indicated in Table I, whereas sample CLL-67 was treated with $20 \mu \mathrm{M}$ quercetin and $10 \mathrm{ng} \mathrm{ml}^{-1}$ rTRAIL. C, Q, T, CD indicate DMSO and quercetin, rTRAIL, anti-CD95 treated cells. Numbers on the left indicate the molecular weight of uncleaved $(120 \mathrm{kDa})$ and cleaved $(85 \mathrm{kDa})$ PARP. Images are representative of one experiment out of two performed for each sample.

The apoptogenic effect of quercetin associated with anti-CD95/ rTRAIL has been also confirmed by the degradation of PARP. Demonstrative examples are shown in Figure 2. In the case of sample CLL-67 (panel A), the combined treatment (quercetin along with rTRAIL) increases PARP degradation compared with single treatments, whereas in the second case (panel B, corresponding to CLL-44), the apoptotic effect of quercetin monotreatment is prevalent, as shown in Table 2 in terms of cell viability, caspase- 3 activation and annexin $\mathrm{V}$ exposure.

In selected samples, which showed an enhancing effect of quercetin associated with DR agonists, we also measured the activation of caspase-9. These experiments were carried out to show the ability of quercetin to trigger the intrinsic apoptotic pathway, which is characterized by release of mitochondrial cytochrome $c$ into the cytosol and procaspase- 9 processing. In the cytosol, cytochrome $c$ binds to apoptosis protease activation factor 1 and the resultant complex recruits caspase-9 leading to its activation and cleavage of downstream caspases (Kuida, 2000). As shown in Figure 3, quercetin monotreatment increases caspase-9 activity by $3.5-$ and 4 -fold in CLL-56 and CLL-55 respectively. This effect was further enhanced in the combined treatments with antiCD95 and rTRAIL (Figure 3), confirming data reported in Table 2. It is interesting to note that increased caspase- 9 by quercetin monotreatment in CLL-56 did not match with a strong activation of caspase- 3 and apoptotic induction (Table 2), which, in turn, was obtained only in the combined treatments.

In the majority of B-CLL cells investigated, quercetin monotreatment induced cell death at concentrations significantly lower than those showing cytotoxicity on cell lines of leukaemic origin (Russo et al, 2007; data not shown). On the basis of this observation, we reasoned that quercetin could also strengthen the efficacy of drugs widely used in the therapy of CLL, such as fludarabine (Yee and O'Brien, 2006). To test this possibility, we treated the samples isolated from B-CLL patients (indicated by footenote $\mathrm{c}$ in Table 1), showing a significant resistance to $3.5-$ $14 \mu \mathrm{m}$ fludarabine, with quercetin in combination with fludarabine. It is noteworthy that $3.5 \mu \mathrm{M}$ represents the therapeutic plasma concentration of fludarabine (Binet, 1993). As reported in Figure 4, the association between quercetin and fludarabine increases cell death by approximately two-fold when compared with quercetin 
646

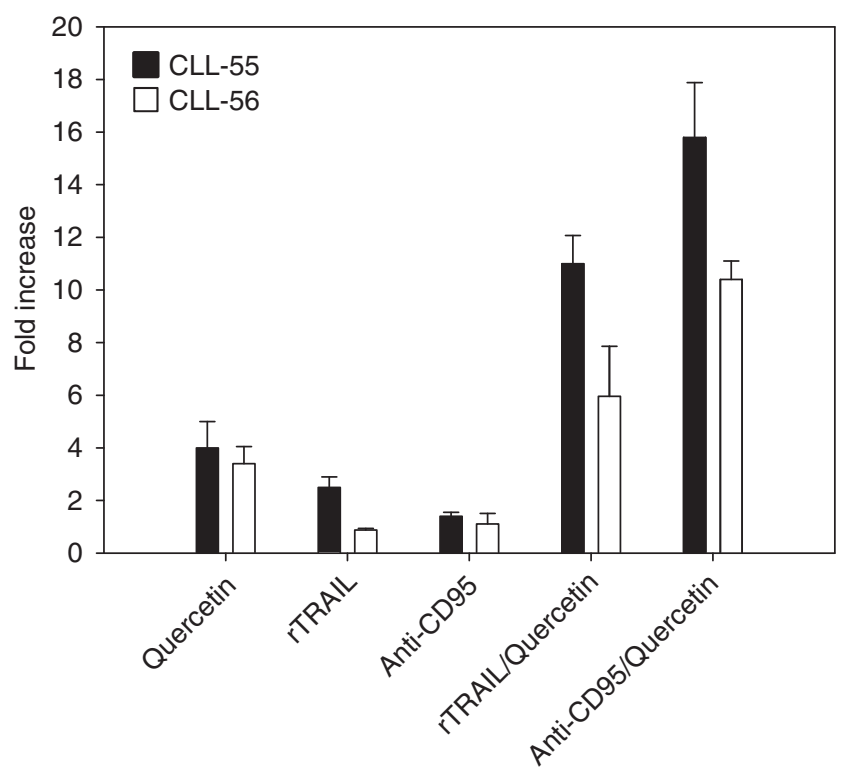

Figure 3 Caspase- 9 activation in cells isolated from CLL patients. The proteolytic activity of caspase- 9 (nmol AFC per min per $\mu$ g protein) was measured in two selected samples isolated from CLL patients (CLL-55 and CLL-56). Cells were treated as indicated in Table 2. Enzymatic activity was reported as -fold increase compared with DMSO-treated cells after $12 \mathrm{~h}$ stimulation. Bar graphs represent the mean of two experiments ( \pm s.e.).

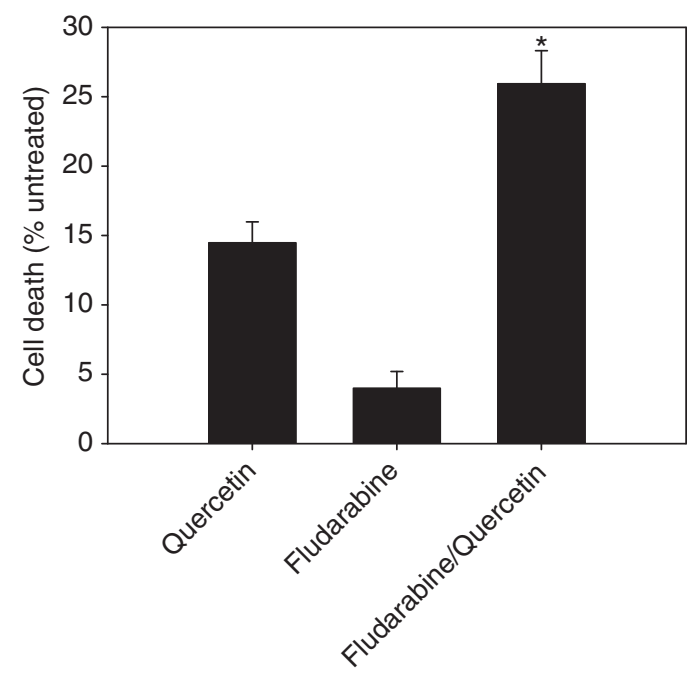

Figure 4 Cell viability assay in cells isolated from CLL patients and treated with quercetin and fludarabine. Range of concentrations used is as reported in Table 3. Values are presented as mean \pm s.e. $(n=29)$ and significant differences were calculated using the two-tailed paired t-test. Asterisk $(*)$ indicates significant difference from quercetin $(P<0.0005)$ and fludarabine $(P<0.000 \mathrm{I})$.

and by six-fold with respect to fludarabine. Differences were significant, as indicated in Figure 4. Selected samples listed in Table 3 show that the pro-apoptotic effects of the combined treatment are more than additive (arrows) with respect to the three markers used to assess cell death, suggesting the enhancing apoptogenic effect of quercetin also in association with fludarabine. The pleiotropic effect of quercetin on multiple cellular targets is exemplified in sample CLL-42, which is resistant to CD95-, TRAIL- (Table 2), and fludarabine-induced (Table 3) apoptosis. Quercetin is not able to bypass resistance to DR agonists, but ameliorates the sensitivity to fludarabine.

\section{DISCUSSION}

The development of high selective drugs triggering specific molecular target is the desirable and ambitious objective in leukaemia treatment. A suitable example is represented by the development of the tyrosine kinase inhibitor imatinib that has revolutionised the treatment of chronic myeloid leukaemia (Stegmeier et al, 2010). However, in the case of CLL, its heterogeneous nature and the resistance to conventional treatments developing in the majority of patients hinder the progresses in therapy. Our study opens new applicative perspectives supported by the observation that TRAIL receptor is preferentially expressed on malignant cells and appears a better candidate in cancer therapy and in B-CLL leukaemias, with respect to the high liver toxicity of anti-CD95 treatment (Igney and Krammer, 2002; MacFarlane et al, 2005).

Overall, this work shows that resistance to DR- and fludarabinemediated cell death in leukaemic cells isolated from B-CLL patients can be ameliorated or bypassed by the combined treatment with quercetin. Similar data have been reported by our group in leukaemia cell lines resistant to DR-induced apoptosis (Russo et al, 1999, 2007). However, as mentioned above, this work represents, to the best of our knowledge, the first evidence that quercetin may potentiate apoptosis in cells isolated from primary tumours.

From data presented in Figures 1-3 and Table 2, we can hypothesise that in leukaemic cells isolated from B-CLL patients, the apoptotic response mediated by DRs could be inhibited, or strongly reduced, by unknown interfering mechanisms functioning on the extrinsic pathways. Quercetin is able to loosen this block potentiating DR-induced apoptosis in CLL cells. This implies the presence of a functional CD95 or TRAIL receptors. Only if this condition is verified quercetin can free the apoptotic pathways downstream CD95/TRAIL that are blocked or inhibited by anti-apoptotic factors. We also suggest that the moderate but significant enhancing effect of quercetin in inducing apoptosis when associated with anti-CD95, rTRAIL, and fludarabine (Figures 1 and 4) can be explained evoking the variability of B-CLL cells and the heterogeneity of the disease.

New combined therapeutic treatments are potential targets against resistant forms of B-CLL (Kaufmann and Steensma, 2005; Pleyer et al, 2009). The possibility that quercetin may ameliorate efficacy of chemotherapy is strengthen by the safety of the molecule administered through intravenous infusion. In fact, an extensive phase I clinical trial established that at dose of $10.8 \mathrm{mg} \mathrm{kg}^{-1}$ body weight, no adverse effects were observed (Ferry et al, 1996). The well-documented safety of quercetin (Okamoto, 2005; Harwood et al, 2007), together with the observation that quercetin does not induce apoptosis in human peripheral mononuclear cells (Lugli et al, 2009; Russo GL, Russo M, Spagnuolo C, data not shown), represents an important issue in favour of its potential use in combination with other therapeutic treatments, already approved and used in clinics.

The mechanism of action triggered by quercetin in CLL is still a matter of study. As partially shown here and in agreement with unpublished data from our laboratory on cell lines (Russo et al, in preparation), quercetin may exert its effect on both extrinsic and intrinsic apoptotic pathways. We confirmed this possibility in B-CLLs with the observation that quercetin triggers both DR- (extrinsic pathway) and fludarabine (intrinsic pathway)induced cell death. The well-known antioxidant properties of the molecule are independent from its apoptogenic activity when associated with DRs or fludarabine. In fact, fluctuation of intracellular reactive oxygen species in B-CLL cells does not correlate with quercetin treatments and/or its cytotoxicity (Supplementary Figure S2). A similar behaviour was reported in leukaemic cell lines (Russo et al, 2003). We also explored other mechanism(s) of action possibly triggered by quercetin. One rationale hypothesis to explain the sensitising apoptotic effect of 
Table 3 Cytotoxic effects of quercetin and fludarabine in cells isolated from CLL patients

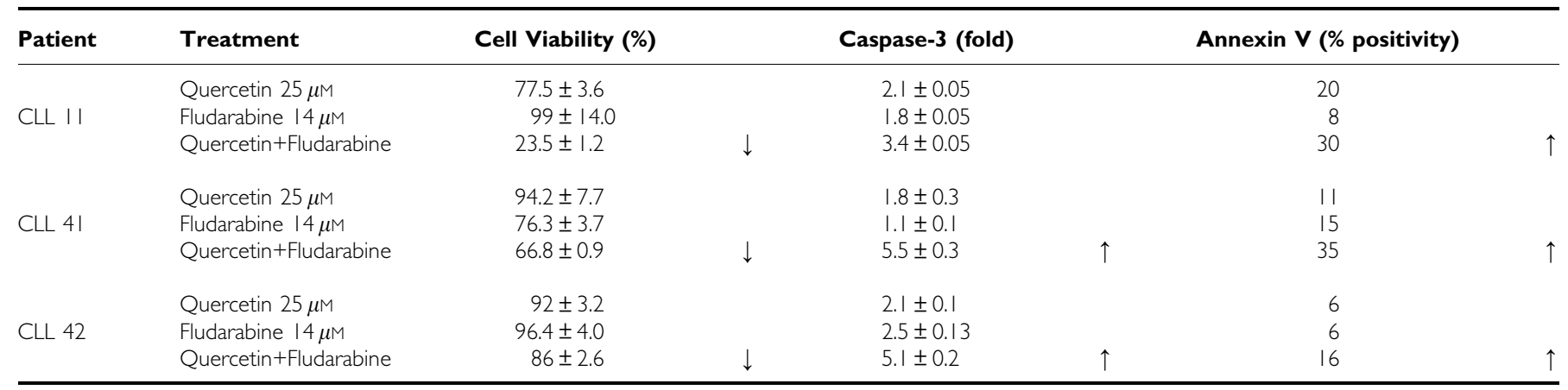

Abbreviation: $\mathrm{CLL}=$ chronic lymphocytic leukaemia. Arrows have the same meaning as in Table 2.

the molecule in rTRAIL-induced cell death could be its ability to stimulate the expression of TRAIL receptor(s). In this context, it is worthwhile to remember that pivotal works from Cohen's group showed that, in B-CLL, TRAIL-R1 is predominantly expressed over TRAIL-R2, whereas no putative decoy receptors, TRAIL-R3 and TRAIL-R4, are present on the surface of B-CLL cells (MacFarlane et al, 2002, 2005). Unfortunately, we showed that quercetin does not modify expression of TRAIL-R1 (Supplementary Figure S3). Alternatively, considering the importance of Bcl-2 family member in controlling apoptosis in B-CLL (Packham and Stevenson, 2005), we tested the ability of quercetin to interfere with $\mathrm{Bcl}-2$ proteins regulation. Pro-apoptotic Bax and anti-apoptotic Bcl-xL cannot be considered important, functional targets of quercetin in B-CLL as their expression is extremely fluctuating in untreated B-CLL cells, probably due to the heterogenicity of the disease (Supplementary Figure S4A and B). In the case of pro-survival member Bcl-2, its expression appears more constant in B-CLL isolated from patients, but it is not influenced by quercetin treatment (Supplementary Figure S4C). Currently, we are screening other possible direct or indirect targets of quercetin that may be able to interfere with apoptotic pathways in cellular models resembling B-CLL.

A novelty of this study is the demonstration that quercetin was able to induce apoptosis in CLL samples in the absence of other treatments (Figures 1 and 4; Table 2 and 3). B cells isolated from patients were more sensitive to quercetin than cell lines of leukaemic origin, which showed neither cytotoxicity, nor apoptosis when treated with $50 \mu \mathrm{m}$ quercetin (Russo et al, 2007). In our view, this represents an important issue that stimulates further studies in the direction of therapeutic use of the molecule. Quercetin in CLLs may function as a double-blade knife combining its intrinsic apoptogenic activity with the ability to potentiate the effect of other chemotherapeutic treatments.

\section{ACKNOWLEDGEMENTS}

CS was supported by a Basic Research Grant (Ricerca Spontanea a Tema Libero) from the Agrofood Department of the Italian National Research Council (CNR, Rome, Italy). We thank all colleagues who provided technical assistance and fruitful discussion to the data presented, especially Dr A Nappo and Dr N Russo.

\section{Conflict of interest}

The authors declare no conflict of interest.

Supplementary Information accompanies the paper on British Journal of Cancer website (http://www.nature.com/bjc)

\section{REFERENCES}

Aggarwal BB, Shishodia S (2006) Molecular targets of dietary agents for prevention and therapy of cancer. Biochem Pharmacol 71(10): $1397-1421$

Binet JL (1993) Fludarabine phosphate in chronic lymphoproliferative diseases. The French Group on CLL. Nouv Rev Fr Hematol 35(1): 5-7

Bischoff SC (2008) Quercetin: potentials in the prevention and therapy of disease. Curr Opin Clin Nutr Metab Care 11(6): 733-740

Bomstein Y, Yuklea M, Radnay J, Shapiro H, Afanasyev F, Yarkoni S, Lishner M (2003) The antiapoptotic effects of blood constituents in patients with chronic lymphocytic leukemia. Eur J Haematol 70(5): $290-295$

Bradford MM (1976) A rapid and sensitive method for the quantitation of microgram quantities of protein utilizing the principle of protein-dye binding. Anal Biochem 72: 248-254

Damle RN, Wasil T, Fais F, Ghiotto F, Valetto A, Allen SL, Buchbinder A, Budman D, Dittmar K, Kolitz J, Lichtman SM, Schulman P, Vinciguerra VP, Rai KR, Ferrarini M, Chiorazzi N (1999) Ig V gene mutation status and CD38 expression as novel prognostic indicators in chronic lymphocytic leukemia. Blood 94(6): 1840-1847

Day AJ, Gee JM, DuPont MS, Johnson IT, Williamson G (2003) Absorption of quercetin-3-glucoside and quercetin- $4^{\prime}$-glucoside in the rat small intestine: the role of lactase phlorizin hydrolase and the sodiumdependent glucose transporter. Biochem Pharmacol 65(7): 1199-1206

Debatin KM, Krammer PH (2004) Death receptors in chemotherapy and cancer. Oncogene 23(16): 2950-2966

Eichhorst BF, Busch R, Hopfinger G, Pasold R, Hensel M, Steinbrecher C, Siehl S, Jager U, Bergmann M, Stilgenbauer S, Schweighofer C, Wendtner CM, Dohner H, Brittinger G, Emmerich B, Hallek M (2006) Fludarabine plus cyclophosphamide versus fludarabine alone in first-line therapy of younger patients with chronic lymphocytic leukemia. Blood 107(3): $885-891$

Fautz R, Husein B, Hechenberger C (1991) Application of the neutral red assay (NR assay) to monolayer cultures of primary hepatocytes: rapid colorimetric viability determination for the unscheduled DNA synthesis test (UDS). Mutat Res 253: 173-179

Ferry DR, Smith A, Malkhandi J, Fyfe DW, deTakats PG, Anderson D, Baker J, Kerr DJ (1996) Phase I clinical trial of the flavonoid quercetin: pharmacokinetics and evidence for in vivo tyrosine kinase inhibition. Clin Cancer Res 2(4): 659-668

Fimognari C, Lenzi M, Hrelia P (2008) Chemoprevention of cancer by isothiocyanates and anthocyanins: mechanisms of action and structure-activity relationship. Curr Med Chem 15(5): 440-447 
Hallek M, Cheson BD, Catovsky D, Caligaris-Cappio F, Dighiero G, Dohner H, Hillmen P, Keating MJ, Montserrat E, Rai KR, Kipps TJ (2008) Guidelines for the diagnosis and treatment of chronic lymphocytic leukemia: a report from the International Workshop on Chronic Lymphocytic Leukemia updating the National Cancer Institute-Working Group 1996 guidelines. Blood 111(12): 5446-5456

Harwood M, Danielewska-Nikiel B, Borzelleca JF, Flamm GW, Williams GM, Lines TC (2007) A critical review of the data related to the safety of quercetin and lack of evidence of in vivo toxicity, including lack of genotoxic/carcinogenic properties. Food Chem Toxicol 45(11): $2179-2205$

Igney FH, Krammer PH (2002) Death and anti-death: tumour resistance to apoptosis. Nat Rev Cancer 2(4): 277-288

Johnson S, Smith AG, Loffler H, Osby E, Juliusson G, Emmerich B, Wyld PJ, Hiddemann W (1996) Multicentre prospective randomised trial of fludarabine versus cyclophosphamide, doxorubicin, and prednisone (CAP) for treatment of advanced-stage chronic lymphocytic leukaemia. The French Cooperative Group on CLL. Lancet 347(9013): $1432-1438$

Kaufmann SH, Steensma DP (2005) On the TRAIL of a new therapy for leukemia. Leukemia 19(12): 2195-2202

Kim JY, Kim EH, Park SS, Lim JH, Kwon TK, Choi KS (2008a) Quercetin sensitizes human hepatoma cells to TRAIL-induced apoptosis via Sp1-mediated DR5 up-regulation and proteasome-mediated c-FLIPS down-regulation. J Cell Biochem 105(6): 1386-1398

Kim YH, Lee DH, Jeong JH, Guo ZS, Lee YJ (2008b) Quercetin augments TRAIL-induced apoptotic death: involvement of the ERK signal transduction pathway. Biochem Pharmacol 75(10): 1946-1958

Kuida K (2000) Caspase-9. Int J Biochem Cell Biol 32(2): 121-124

Lamson DW, Brignall MS (2000) Antioxidants and cancer, part 3: quercetin. Altern Med Rev 5(3): 196-208

Lugli E, Ferraresi R, Roat E, Troiano L, Pinti M, Nasi M, Nemes E, Bertoncelli L, Gibellini L, Salomoni P, Cooper EL, Cossarizza A (2009) Quercetin inhibits lymphocyte activation and proliferation without inducing apoptosis in peripheral mononuclear cells. Leuk Res 33(1): $140-150$

MacFarlane M, Harper N, Snowden RT, Dyer MJ, Barnett GA, Pringle JH, Cohen GM (2002) Mechanisms of resistance to TRAIL-induced apoptosis in primary B cell chronic lymphocytic leukaemia. Oncogene 21(44): $6809-6818$

MacFarlane M, Inoue S, Kohlhaas SL, Majid A, Harper N, Kennedy DB, Dyer MJ, Cohen GM (2005) Chronic lymphocytic leukemic cells exhibit apoptotic signaling via TRAIL-R1. Cell Death Differ 12(7): 773-782

Mansour A, Chang VT, Srinivas S, Harrison J, Raveche E (2007) Correlation of ZAP-70 expression in B cell leukemias to the ex vivo response to a combination of fludarabine/genistein. Cancer Immunol Immunother 56(4): $501-514$

Murakami A, Ashida H, Terao J (2008) Multitargeted cancer prevention by quercetin. Cancer Lett 269(2): 315-325

Okamoto T (2005) Safety of quercetin for clinical application (Review). Int J Mol Med 16(2): 275-278

Packham G, Stevenson FK (2005) Bodyguards and assassins: Bcl-2 family proteins and apoptosis control in chronic lymphocytic leukaemia. Immunology 114(4): 441 - 449

Papenfuss K, Cordier SM, Walczak H (2008) Death receptors as targets for anti-cancer therapy. J Cell Mol Med 12(6B): 2566-2585

Pleyer L, Egle A, Hartmann TN, Greil R (2009) Molecular and cellular mechanisms of CLL: novel therapeutic approaches. Nat Rev Clin Oncol 6(7): $405-418$

Psahoulia FH, Drosopoulos KG, Doubravska L, Andera L, Pintzas A (2007) Quercetin enhances TRAIL-mediated apoptosis in colon cancer cells by inducing the accumulation of death receptors in lipid rafts. Mol Cancer Ther 6(9): 2591-2599

Russo GL (2007) Ins and outs of dietary phytochemicals in cancer chemoprevention. Biochem Pharmacol 74(4): 533-544

Russo M, Mupo A, Spagnuolo C, Russo GL (2010) Exploring death receptor pathways as selective targets in cancer therapy. Biochem Pharmacol 8(5): 674-682

Russo M, Nigro P, Rosiello R, D’Arienzo R, Russo GL (2007) Quercetin enhances CD95- and TRAIL-induced apoptosis in leukemia cell lines. Leukemia 21(5): $1130-1133$

Russo M, Palumbo R, Mupo A, Tosto M, Iacomino G, Scognamiglio A, Tedesco I, Galano G, Russo GL (2003) Flavonoid quercetin sensitizes a CD95-resistant cell line to apoptosis by activating protein kinase Calpha. Oncogene 22(21): $3330-3342$

Russo M, Palumbo R, Tedesco I, Mazzarella G, Russo P, Iacomino G, Russo GL (1999) Quercetin and anti-CD95(Fas/Apo1) enhance apoptosis in HPB-ALL cell line. FEBS Lett 462(3): 322-328

Schroers R, Griesinger F, Trümper L, Haase D, Kulle B, Klein-Hitpass L, Sellmann L, Dührsen U, Dürig J (2005) Combined analysis of ZAP-70 and CD38 expression as a predictor of disease progression in B-cell chronic lymphocytic leukemia. Leukemia 19(5): 750-758.

Siegelin MD, Reuss DE, Habel A, Rami A, von Deimling A (2009) Quercetin promotes degradation of survivin and thereby enhances death-receptormediated apoptosis in glioma cells. Neuro Oncol 11(2): 122-131

Stegmeier F, Warmuth M, Sellers WR, Dorsch M (2010) Targeted cancer therapies in the twenty-first century: lessons from imatinib. Clin Pharmacol Ther 87(5): 543-552

Yee KW, O'Brien SM (2006) Chronic lymphocytic leukemia: diagnosis and treatment. Mayo Clin Proc 81(8): 1105-1129 